\title{
MODELOS FÍSICOS NA PRÁTICA DE PROJETO DE EDIFÍCIOS: UMA EXPERIÊNCIA DIDÁTICA
}

PHYSICAL MODELS IN BUILDING DESIGN PRACTICE: A DIDACTIC EXPERIMENT

\section{FLORIO, WILSON}

Doutor, Faculdade de Arquitetura e Urbanismo da Universidade Presbiteriana Mackenzie. Email: wilsonflorio@gmail.com

\section{TAGLIARI, ANA}

Doutora, Faculdade de Engenharia Civil Arquitetura e Urbanismo da Universidade Estadual de Campinas. Email: anatagliari@fec.unicamp.br

\section{RESUMO}

0 foco deste artigo é discutir estratégias de ensino de modelagem física que estimulem a reflexão sobre a prática, a criatividade e, ao mesmo tempo, amparem o processo de concepção de projeto de edifícios. 0 objeto de estudo é o modelo físico manual no contexto da prática projetual. 0 artigo relata uma experiência didática ocorrida no ano de 2014. Foram propostos dois exercícios com a intenção de conceber um edifício a partir de diferentes tipos de modelos físicos. Os resultados obtidos permitem afirmar que cada tipo de artefato produzido pelo estudante de arquitetura facilita a produção e a exploração de diferentes ideias durante o processo de concepção de projeto de edifício, e, particularmente, que a imersão na busca por soluções depende da motivação intrínseca e da suspensão de conclusões apressadas.

PALAVRAS-CHAVE: processo de projeto; modelo físico; reflexão-na-ação; criatividade; tangibilidade.

\section{ABSTRACT}

The focus of this paper is to discuss physical modeling teaching strategies that encourage reflection on practice, creativity and at the same time, support the design process of buildings. The object is the study of physical models in the context of design practice. The article reports a teaching experience that took place in the year 2014. Two exercises were proposed with the intention of designing a building using different types of physical models. The results allow us to affirm that each type of artifact produced by architecture student facilitates production and exploration of different ideas during the design process of building, and particularly that immersion in the search for solutions depends on intrinsic motivation and the suspension of hasty conclusions.

KEYWORDS: design process; physical model; reflection-in-action; creativity; tangibility. 


\section{INTRODUÇÃO}

Este artigo apresenta uma experiência didática realizada na disciplina Modelos e Maquetes no Curso de Arquitetura e Urbanismo da Universidade Estadual de Campinas, ocorrida no ano de 2014. A partir dos conceitos de importantes educadores como Donald Schön, Carl Rogers, John Dewey, David Perkins e Daniel Kahneman, o objetivo é destacar como conhecimentos, experiências e habilidades adquiridos durante os exercícios práticos, amparados por modelos físicos, podem auxiliar as decisões arquitetônicas durante a concepção de um projeto edifício.

A natureza do processo de projeto, no âmbito da arquitetura, impõe que sucessivas ideias sejam experimentadas por meio do uso de diferentes tipos de artefatos - desenhos, modelos físicos, diagramas, modelos digitais, de modo a avançar em direção às possíveis soluções. Os modelos físicos são mais concretos e mais tangíveis do que os desenhos, pois a tridimensionalidade facilita a compreensão da posição relativa de cada elemento no espaço, contribuindo para sua apreensão mais imediata, que ocorre tanto pela visão como pelo tato. Os conhecimentos, as experiências e as habilidades decorrentes da intensa manipulação de artefatos físicos conduzem o estudante a entender a natureza do espaço proposto e sua materialidade, intensificando aquilo que o educador Donald Schön denominou como reflexão-na-ação.

É notável como a exploração de formas complexas nas últimas duas décadas impeliu a produção de modelos físicos e digitais com maior capacidade de visualização dos espaços e elementos constituintes do edifício. Em particular, nota-se como a hibridação de técnicas de representação na atualidade tem contribuído para a cognição em projeto. Consequentemente, a proliferação de modelos físicos, seja pelo método manual tradicional, seja com o auxílio de tecnologias digitais, é decorrente da necessidade de investigação das novas formas dos edifícios, assim como pela facilidade de produção por recursos digitais, como a cortadora a laser.

Entretanto, a demasiada confiança nas tecnologias de fabricação digital 2D, como a cortadora a laser, ou $3 \mathrm{D}$, como a prototipagem rápida (processo aditivo), ou ainda, máquinas CNC (processo subtrativo), e o uso precoce desses recursos, podem dificultar ou mesmo impedir que os estudantes aprendam primeiramente a pensar e organizar formas e espaços tridimensionalmente. Não há dúvida que o aprendizado e a exploração das novas tecnologias é fundamental, e que conduz a resultados mais rápidos e mais precisos, sobretudo para aqueles que já aprenderam as noções básicas de como projetar e materializar suas ideias pelo processo manual tradicional. Este aspecto não está em discussão. O problema principal é que esse "atalho" tem sido prejudicial ao aprendizado inicial do aluno ingressante no curso de arquitetura, pois os processos manuais ainda mantêm um papel importante na formação dos estudantes, e contribuem para o desenvolvimento do raciocínio espacial, que posteriormente será fundamental para explorar os recursos de fabricação digital.

O presente artigo está estruturado em cinco sessões. Após esta introdução, são tratados os conceitos norteadores da pesquisa realizada. Na terceira parte são explicitadas as intenções subjacentes a cada uma das etapas de realização de cada exercício, e, em destaque, as orientações ocorridas durante sua realização. Na sessão seguinte os resultados obtidos em cada etapa são apresentados. Por fim, na quinta e última sessão, denominada Discussão, é realizada uma reflexão sobre os resultados obtidos, e, particularmente, destaca as contribuições do artigo para a reflexão sobre o ensino de modelagem e sua íntima relação com a prática de projeto.

\section{CONCEITOS E ANTECEDENTES}

Os exercícios realizados nesta experiência didática, e relatados neste texto, serão devidamente pormenorizados, analisados e discutidos nas sessões 3, 4 e 5, respectivamente. Porém, primeiramente serão apresentados os principais conceitos que fundamentaram e nortearam as ações dos professores durante as aulas.

\section{Reflexão-na-ação e o Processo de Projeto}

O processo de projeto no ateliê depende fundamentalmente da capacidade de se estabelecer uma comunicação efetiva entre professor-aluno, em particular por meio dos artefatos que são compartilhados entre eles. Além das descrições verbais, é por intermédio de desenhos e de modelos (físicos ou digitais) que todos se comunicam em sala de aula. Contudo, essa relação requer mútua confiança e boa organização de conteúdo, para que o processo de ensino-aprendizagem ocorra de modo satisfatório.

É importante apontar que boa parte dessa comunicação ocorre por meio de breves abordagens paulatinas de discussão, sobre os problemas e subproblemas que se apresentam a cada instante do processo de projeto. Após o professor apresentar o projeto a ser realizado, o estudante inicia sua investigação sem 
saber exatamente o que deve ser feito, e também sem saber o que conseguirá alcançar no final deste processo. O educador Donald Schön descreveu este delicado momento:

\begin{abstract}
O ateliê de projeto baseia-se em uma resposta implícita ao paradoxo e ao dilema de aprender a projetar: o estudante deve começar a atividade de projeto antes de saber o que está fazendo, de modo que as demonstrações e as descrições do instrutor do ateliê possa (sic) assumir significados úteis para seu design posterior. Contudo, esse 'círculo virtuoso' depende da capacidade do instrutor do ateliê e do estudante de comunicarem-se efetivamente um com o outro, apesar do potencial para ser vago, ambíguo ou obscuro, inerente às coisas que eles tentam comunicar (SCHÖN, 2000, p.83).
\end{abstract}

Esse momento difícil, de dúvida e de incerteza no ateliê, só pode ser superado a partir do empenho do estudante no registro de suas ideias, assim como do desempenho do professor para monitorar e instruir as ações do estudante durante a elaboração do projeto. Consequentemente, os desafios e os obstáculos só podem ser suplantados a partir da produção de diferentes ideias, por tentativa e erro, por avanços em pequenos ciclos de análise-síntese-avaliação. Sob a orientação do professor, o estudante deve fazer e refazer, pensar e debater, de modo a aprender e incorporar, na prática, conceitos, e, assim, tomar iniciativas para resolver os problemas que se apresentam nos três principais domínios estabelecidos pela forma, função e técnica.

Arquitetos e estudantes de arquitetura materializam ideias em artefatos de modo a registrar o que está sendo pensado a cada momento do processo de projeto. Quando solicitados a explicar o que fizeram tendem a elaborar descrições incompletas e imprecisas. Esse é um fato muito conhecido pelos professores. Schön (1992) coloca assim essa questão:

[...] designers know more than they can say, tend to give inaccurate descriptions of what they know, and can best (or only) gain access to their knowing-in-action by putting themselves into the mode of doing [...] (SCHÖN, 1992, p.131)

A afirmação acima nos permite inferir que os artefatos produzidos durante o processo de projeto demonstram os conhecimentos implícitos contidos neles mesmos. O modo de fazer revela parte do pensamento do projetista, demonstrando que o conhecimento é revelado na própria ação de fazer. Assim, pensar e fazer estão intimamente interligados nos próprios artefatos que são produzidos a cada situação projetual. Neste sentido, é desejável que o professor seja capaz de instruir e incentivar os estudantes a materializar suas ideias de um modo reflexivo, intercalando o pensar e o fazer.

Quando alguém aprende uma prática, é iniciado nas tradições de uma comunidade de profissionais que exercem aquela prática e no mundo prático que eles habitam. Aprende suas convenções, seus limites, suas linguagens e seus sistemas apreciativos, seu repertório de modelos, seu conhecimento sistemático e seus padrões para o processo de conhecer-na-ação (SCHÖN, 2000, p.39).

Os desenhos e os modelos físicos (ou digitais) que são elaborados pelos estudantes carregam consigo as convenções estabelecidas pela prática. As tradições da prática são incorporadas no encadeamento das ações executadas pelos projetistas. Assim, mais do que meros artefatos, desenhos e modelos tridimensionais contêm, implicitamente, conhecimentos acumulados de um modus operandi de arquitetos. Cabe ao professor orientar essas ações e conscientizar os estudantes sobre a natureza da prática de projeto.

No presente artigo, as instruções fornecidas pelos professores na elaboração dos modelos físicos ocorreram no intuito de introduzir o universo da prática no ateliê, de modo reflexivo e ativo. A ideia central é orientar os estudantes a explorar os modelos físicos não meramente como um meio de representação, mas como artefatos que auxiliam ativamente a geração de ideias e a concepção dos espaços arquitetônicos durante a prática de projeto.

\title{
Aprender a apreender
}

Nos anos 60, o educador Carl Rogers (1978) se destacou quando apontou a importância da liberdade da aprendizagem significativa e experiencial, da empatia na relação professor-aluno e, sobretudo, na elaboração do conceito de "aprender a apreender".

Segundo Rogers, o professor deveria assumir o autêntico papel de facilitador de aprendizado. Além disso, o educador explica a importância de trabalhar sobre "problemas percebidos como reais". Neste entendimento, pode-se pensar o ensino de projeto a partir de experiências significativas, próximas a problemas reais, cotidianos, inerentes ao aprendizado do ofício de arquiteto, onde o professor atua como um facilitador, colocando-se à disposição para esclarecer dúvidas e provocar questionamentos. 
Nesta visão, a aprendizagem significativa é verificada "quando o estudante percebe que a matéria a estudar se relaciona com os seus próprios objetivos" (ROGERS, 1978, p.160). Além disso, o educador destaca que "é por meio de atos que se adquire aprendizagem mais significativa" (1978, p.163). Logo se percebe que a qualidade do aprendizado depende substancialmente do envolvimento do aluno com aquilo que, de fato, ele precisa e quer aprender durante o processo de projeto.

\section{Tangibilidade e Multimodalidade: Hibridação dos meios de representação}

Modelos físicos oferecem benefícios de acessibilidade, tangibilidade, manipulabilidade e engajamento colaborativo. Para esses propósitos, modelos reais são usados em todas as escalas, variando desde planejamento urbano até a exploração de subcomponentes de um edifício em particular (KVAN; THILAKARATNE, 2003, p.6).

Recentes estudos sobre tangibilidade apontam a importância de operar simultaneamente no meio físico e no meio digital. Embora a tecnologia computacional tenha assumido mais aspectos formais no processo de projeto, ela não tem sido capaz de dominar os processos de projeto tradicionais (OEHLBERG; LAU; AGOGINO, 2009, p.237).

Diante do desafio de promover conhecimentos duradouros e desenvolver habilidades, de um modo criativo e crítico, é essencial o entendimento que o processo de projeto exige um monitoramento, que requer um acompanhamento dos principais momentos decisórios. Para isso é necessário entender a sequência de produção dos artefatos multimodais produzidos, sejam eles manuais (artesanais) sejam eles tecnológicos (computacionais).

No âmbito da educação, o conceito de representação multimodal refere-se à integração dos diferentes modos de expressão presentes durante a realização do pensamento. A exploração de um problema de projeto, por diferentes meios de expressão e de representação, facilita o entendimento de conceitos sob diferentes pontos de vista. Cada meio possui aspectos fortes e fracos em termos de precisão, clareza e significados, que, somados, permitem aos estudantes e aos arquitetos investigar o mesmo assunto, ou conceito, sob diversos vieses.

Ainsworth (1999), Ainsworth \& Vanlabeke (2004) e Prain \& Waldrip (2006) afirmaram que, para aprender algo de modo efetivo, os estudantes devem entender diferentes representações de conceitos e de processos, e serem capazes de traduzi-los um em outro, assim como entender o uso coordenado entre as representações de um conhecimento científico. Neste sentido, parece fundamental a necessidade de entender que os diferentes modos de expressão e de representação, usados para diferentes propósitos, tornam-se complementares entre si.

Mas o conceito de multimodalidade pode se referir à combinação de conhecimentos e informações visuais obtidas por múltiplos meios de expressão e de representação. Nesse sentido, Aksamija lordanova (2010) refere-se à multimodal como os diferentes modos de expressar os conhecimentos implícitos e explícitos, seja pela integração de conhecimentos obtidos por dados abstratos, tais como algoritmos e textos, seja pelas várias combinações de diferentes representações visuais, como desenhos, imagens, maquetes ou modelos virtuais.

Os múltiplos tipos de representações em arquitetura fornecem informações complementares, uma vez que uma única representação seria insuficiente para produzir toda a informação necessária para comunicar os múltiplos aspectos de um determinado domínio. Com a orientação dos professores, as múltiplas representações podem apoiar a construção de uma discussão e compreensão mais profunda sobre o projeto em questão. Assim, quando os estudantes investigam ativamente as informações contidas em seus projetos, e as integram de um modo coordenado, a comunicação de ideias para si mesmo, e para os outros, se torna mais intensa e profícua.

\section{Tomada de Decisões e o Pensamento Reflexivo}

A origem do pensamento reflexivo, segundo o filósofo e educador John Dewey (1910), ocorre em momentos de dúvida ou de perplexidade. É a dificuldade de encontrar uma solução imediata que obriga o sujeito a pensar. Dewey (1910, p.13) aponta um ponto extremamente importante para que o pensamento reflexivo ocorra: suspensão temporária de conclusões. Esse fato é da maior importância no processo de projeto, onde a dúvida e a incerteza estão fortemente presentes, sobretudo no estágio inicial da investigação.

Durante o processo de projeto é fundamental produzir diferentes ideias e diversas possibilidades de solução para cada problema que se apresente. Para tanto o professor deve incentivar uma ampla investigação, e fazer com que o estudante retarde a seleção de uma solução, de modo a fazê-lo pensar o maior tempo possível sobre os problemas inerentes a cada fase do processo. Mas há algumas dificuldades de pensar, sobretudo de modo produtivo e reflexivo. 
David Perkins (1995, p.153) definiu tipos de pensamento decorrentes da dificuldade de pensar, notando a tendência humana de pensar de modo apressado (impulsivo e insuficiente no exame profundo de alternativas), limitado (falha ao desafiar pressupostos ou para examinar outros pontos da vista), nebuloso (descuidado, impreciso, cheio de combinações), e alastrado (desorganização geral, falha para avançar ou para concluir). Estes tipos de pensamento podem ser facilmente identificados durante a orientação de práticas projetuais.

Nos seus estudos sobre como as pessoas "pensam", o educador Daniel Kahneman (2011, p.80) afirma que na dúvida e na incerteza somos normalmente guiados pela experiência. Esta conclusão é contundente, pois nos leva a inferir que se os estudantes não forem devidamente assistidos durante a realização das tarefas, as decisões tomadas por eles podem ser falhas. O perigo de dar um salto para algum tipo de conclusão apressada, sem previamente ter analisado a situação de projeto, é grande, acarretando um dos mais graves problemas de aprendizado no processo de projeto.

É natural que no momento que um projeto acadêmico é apresentado aos estudantes, eles tendam a querer resolvê-lo o mais rápido possível, provavelmente para se "livrar" da tarefa que Ihes foi imputada. Este pensamento apressado tem sérias implicações nos futuros hábitos na solução de problemas. Por conseguinte, os fatos apontados nos levam a concluir que os exercícios acadêmicos, elaborados pelos professores, deveriam ser cuidadosamente pautados por questões que estimulem os estudantes a pensar de modo mais reflexivo. Além disso, um dos aspectos mais importantes no processo de projeto é tornar o aluno capaz de desmembrar um problema em subproblemas, de modo a retardar soluções precoces, e conduzi-lo a uma reflexão e ao enfrentamento cauteloso sobre cada um deles, com afinco e parcimônia.

Como bem apontou Baron et. al. (1993), as respostas mais imediatas a uma determinada tarefa são normalmente pautadas pela frequência daquilo ter ocorrido no passado e da probabilidade de ocorrer como verdadeiro no futuro. Atividades didáticas inovadoras têm a propriedade de instigar os estudantes a rever seus próprios pontos de vista. Diante destes fatos, é necessário promover atividades didáticas que instiguem os estudantes a pensar, não apenas baseado em conhecimentos e experiências anteriores, mas que despertem o interesse pelo desconhecido.

\section{Motivação}

A motivação é crucial para o desenvolvimento cognitivo dos estudantes, sobretudo no que diz respeito à qualidade do pensamento criativo. Percebe-se nitidamente que aqueles estudantes que desafiam a si próprios em determinada tarefa são mais produtivos em termos de qualidade de ideias, enquanto que aqueles que esperam ser recompensados pela execução de tarefas parecem estar mais interessados em obter boas notas. Logicamente estes são apenas dois pontos extremos do problema da motivação. Mas nota-se que essa grande diferença ocorre porque o primeiro tipo de motivação é intrínseca, e, portanto, advém de uma vontade interior de alcançar algo, enquanto que a segunda é extrínseca, estimulada externamente, num desejo de alcançar rapidamente apenas resultados que interessam. Como será visto adiante, a abordagem que foi estimulada nos exercícios realizados na disciplina Modelos e Maquetes foi a motivação intrínseca, que produz maiores efeitos na qualidade do pensar.

Mas segundo Molden \& Higgins (apud RITCHHART; PERKINS, 2005, p. 776), "nós temos uma tendência natural para favorecer nossa própria posição e interesse - propensão de defender meu ponto de vista", que pode conduzir a conclusões pobres na tomada de decisão e nos discernimentos sobre a verdade (BARON et al., 1993). De fato, nota-se claramente que os estudantes obtêm um aprendizado mais duradouro e significativo quando são totalmente absorvidos pelo trabalho que estão realizando, o que os conduz a absoluta imersão, justamente por acreditar que o trabalho trará recompensas internas a longo prazo. Como resultado o trabalho deste tipo de estudante torna-se mais investigativo e, portanto, mais criativo, sobretudo pelas descobertas inesperadas que encontra durante a sua realização.

\section{PESQUISA REALIZADA: EXERCÍCIOS}

A pesquisa realizada em 2014 envolveu 30 alunos da disciplina Modelos e Maquetes no $3^{\circ}$ semestre do Curso de Arquitetura do Curso de Arquitetura e Urbanismo da Unicamp. Esta disciplina está inserida na sequência de Representação, constituída por Desenho Técnico, Desenho de Observação, Plástica e Informática Aplicada I a IV, ministradas entre o $1^{\circ} \mathrm{e} o 4^{\circ}$ semestre.

Durante 16 semanas, com aula semanal com duração de 4 horas, os exercícios projetuais foram os seguintes: $1^{\circ}$ Exercício: Dobraduras; $2^{\circ}$ Exercício: Projeto do Pavilhão Amilcar de Castro; $3^{\circ}$ Exercício: Geodésica; $4^{\circ}$ Exercício: Maquete de uma residência na cortadora a laser. 
Na primeira aula foi apresentada a ementa, o conteúdo programático, os exercícios a serem realizados e os critérios de avaliação. Foram enfatizados os conceitos preliminares, norteadores das ações na disciplina, sobre a natureza do processo de projeto em arquitetura e o papel dos meios de representação e sua hibridação na atualidade. Durante a segunda e a terceira aula foi realizado o exercício denominado "dobraduras". Da terceira à nona aula foi realizado o exercício denominado "Pavilhão Amilcar de Castro". Na 10a . e 11a. aula foi realizado o exercício que explorou estruturas em forma de geodésicas, com canudos de plástico. E, por fim, da 12 ${ }^{a}$. a 15a . aula foi realizada a maquete de uma residência com o auxílio da cortadora a laser, a partir de um desenho realizado numa disciplina de Informática. Neste artigo serão discutidos apenas os dois primeiros exercícios.

\section{$1^{\circ}$ Exercício: Dobraduras}

O primeiro breve exercício foi realizado em apenas duas aulas, com a duração total de 8 horas/aula. A intenção foi explicar as relações entre a expressão no plano e a expressão no espaço. As quatro etapas foram as seguintes: i) Introdução sobre o conceito de "corte e dobra", estabelecido pelo escultor Amilcar de Castro; ii) Elaboração de modelos de esculturas, em escala reduzida, com papel paraná a partir do conceito enunciado, com a finalidade de aplicá-lo na produção de elementos arquitetônicos constituídos por dobras; iii) Elaboração de desenhos de observação para estudar a tridimensionalidade e as sombras próprias e projetadas dos modelos físicos; iv) Discussão coletiva sobre os resultados obtidos.

Durante a aula expositiva, com duração de uma hora, foi apresentada a obra de Amilcar de Castro, destacando o processo criativo do escultor. O conceito de "corte e dobra" foi exposto aos estudantes com o intuito de explicitar as etapas de concepção e de desenvolvimento de uma escultura a partir dos artefatos produzidos pelo artista: croquis, modelos físicos, esculturas em tamanhos reduzidos e escultura na escala real (Fig. 1). Na sequência os estudantes iniciaram a elaboração dos primeiros estudos de dobras com folhas de papel sulfite 90, 120 e 150 gramas.

Figura 1: Fotos de desenhos e modelos físicos produzidos pelo escultor Amilcar de Castro.
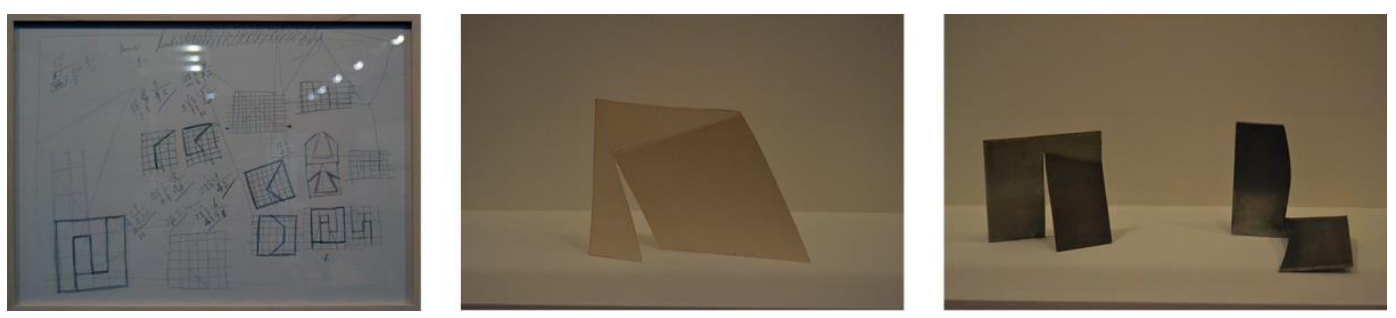

Fonte: Florio e Tagliari, 2015.

Figura 2: Dobraduras e desenhos realizados para o $1^{\circ}$ exercício.
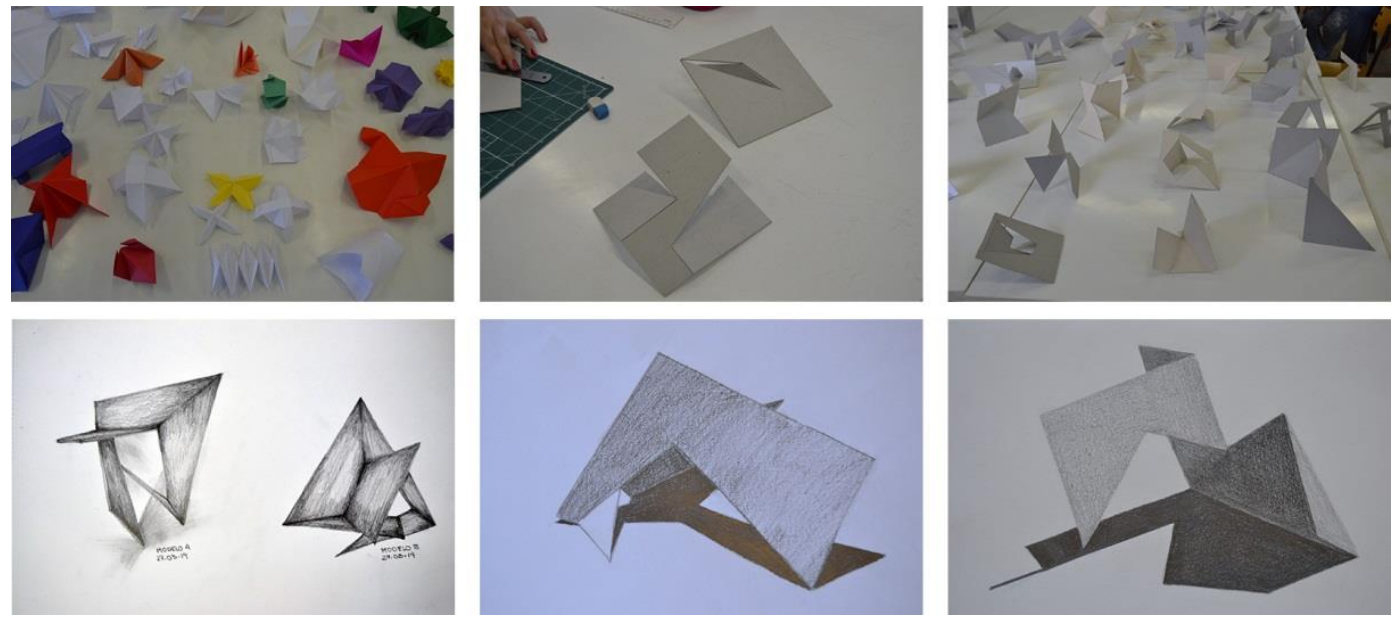

Fonte: Florio e Tagliari, 2015.

Na primeira aula deste exercício os estudantes exploraram formas variadas de dobraduras, com diferentes espessuras de papéis, de modo a perceber a relação entre estes fatores no enrijecimento da forma tridimensional (Fig. 2). Foram discutidos conceitos básicos de geometria para definição das superfícies a serem dobradas.

$\mathrm{Na}$ segunda aula os alunos foram incentivados a realizar diferentes propostas de esculturas a partir de uma superfície quadrada $(15 \times 15 \mathrm{~cm})$. Solicitou-se que os estudantes traçassem linhas auxiliares em grafite 
sobre o papel, de modo a balizar a exploração de alternativas de corte e de dobra, de modo similar ao escultor Amilcar de Castro. Também foi solicitado que cada estudante produzisse diferentes desenhos de observação dos mesmos modelos para estudar relações entre parte e todo, luz e sombra, e áreas opacas e áreas vazadas (Fig. 2). Os desenhos foram entregues durante as três aulas seguintes.

\section{$2^{\circ}$ Exercício: Projeto do Pavilhão Amilcar de Castro}

O segundo exercício foi realizado em sete etapas: i) Explicação do programa de necessidades e áreas máximas; ii) apresentação dos Pavilhões de Artistas e da área de intervenção em Inhotim; iii) Elaboração de estudos volumétricos em isopor; iv) Elaboração de modelos em papel duplex e/ou papel paraná; v) Produção final da maquete de apresentação em poliestireno; vi) Produção de desenhos de observação a partir da maquete final; vii) Discussão coletiva sobre os resultados obtidos.

A intenção deste exercício foi estabelecer relações entre o ensino de modelos e maquetes e o de projeto no atelier. Neste sentido, o exercício não se restringiu a meramente explicar as triviais técnicas de como produzir uma maquete, ao contrário, visava despertar o interesse do estudante pelos modelos físicos como suporte do pensamento projetual.

Foi estabelecido um programa de necessidades contendo seis salas de $90 \mathrm{~m} 2$ cada para exposição de parte do acervo do escultor Amilcar de Castro. Foram solicitadas salas destinadas a abrigar desenhos, modelos físicos, maquetes, pinturas, esculturas de pequeno porte e esculturas de grande porte, produzidos pelo escultor durante toda a sua carreira. O tema era desconhecido pelos estudantes, contribuindo para não terem pré-conceitos, e, portanto, sem ideias fixas.

Alguns parâmetros foram adotados. A área coberta máxima não poderia exceder $600 \mathrm{~m} 2$. 0 terreno, com topografia em aclive, conduziu a adoção de um gabarito de altura entre dois e três pavimentos. Foi solicitado que houvesse espaços cobertos e descobertos para exposição do acervo permanente. Incentivouse a criação de espaços com pé-direito duplo e pátios internos. O edifício poderia estar contido dentro de uma área máxima de 50 por 50 metros, e possuir boa iluminação natural.

Diante das condicionantes acima descritas, os estudantes iniciaram seus estudos delimitando a área máxima de $50 \times 50$ na placa de isopor de $3 \mathrm{~cm}$ de altura, correspondendo a um pé-direito mínimo de 3 metros, na escala 1:100.

Figura 3: Modelos volumétricos iniciais de isopor, produzidos pelos estudantes para o $2^{\circ}$ exercício.
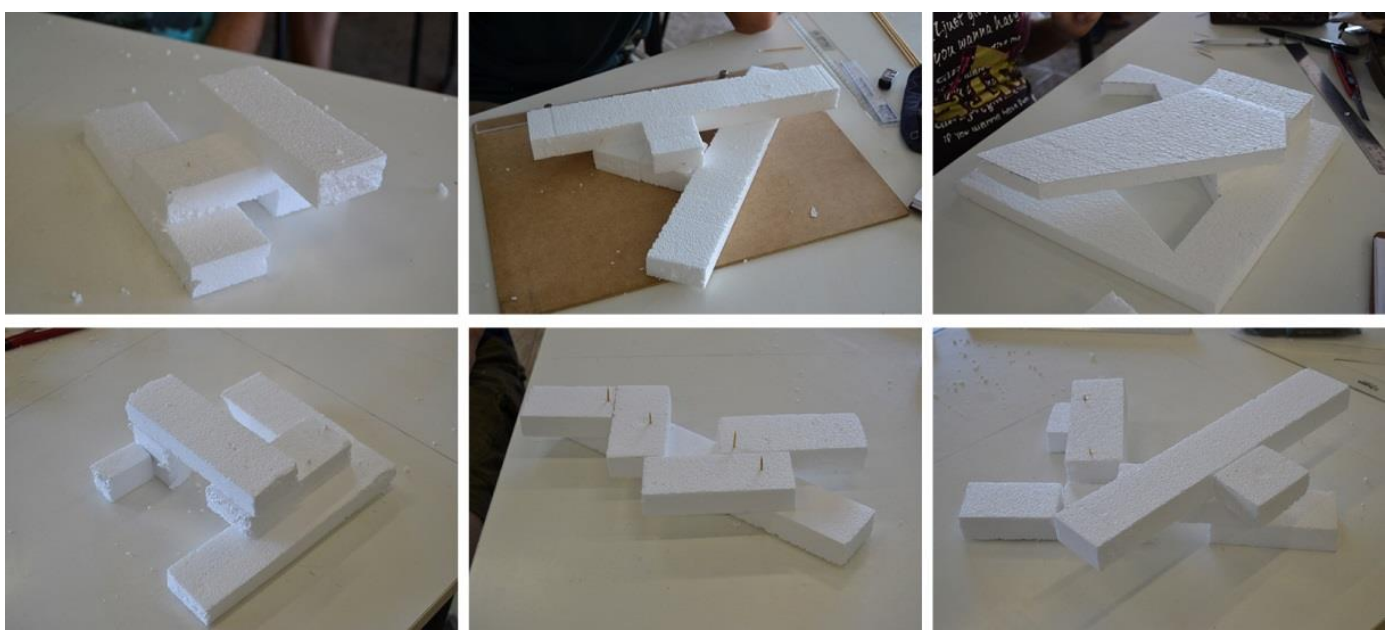

Fonte: Florio e Tagliari, 2015.

Inicialmente os estudantes ficaram receosos em cortar as placas de isopor e dar início ao projeto. Mas, com um incentivo dos professores, eles iniciaram diferentes estudos volumétricos na escala 1:100. Nesta fase também foi estimulada a produção de diferentes ideias, sem se fixar precocemente em nenhuma delas. Neste sentido, solicitou-se que os alunos explorassem as possibilidades de organização espacial dos diferentes setores, posicionando partes correspondentes aos itens do programa por meio de modelos volumétricos (Fig. 3).

$\mathrm{Na}$ etapa seguinte foram elaborados modelos constituídos por superfícies, em papel duplex e/ou papel paraná (Fig. 4). O objetivo na produção deste tipo de modelo foi investigar os espaços internos, as relações espaciais entre pavimentos, e suas relações com os espaços externos. 
Figura 4: Modelos formados por superfícies, produzidos pelos estudantes para $\circ 2^{\circ}$ exercício.
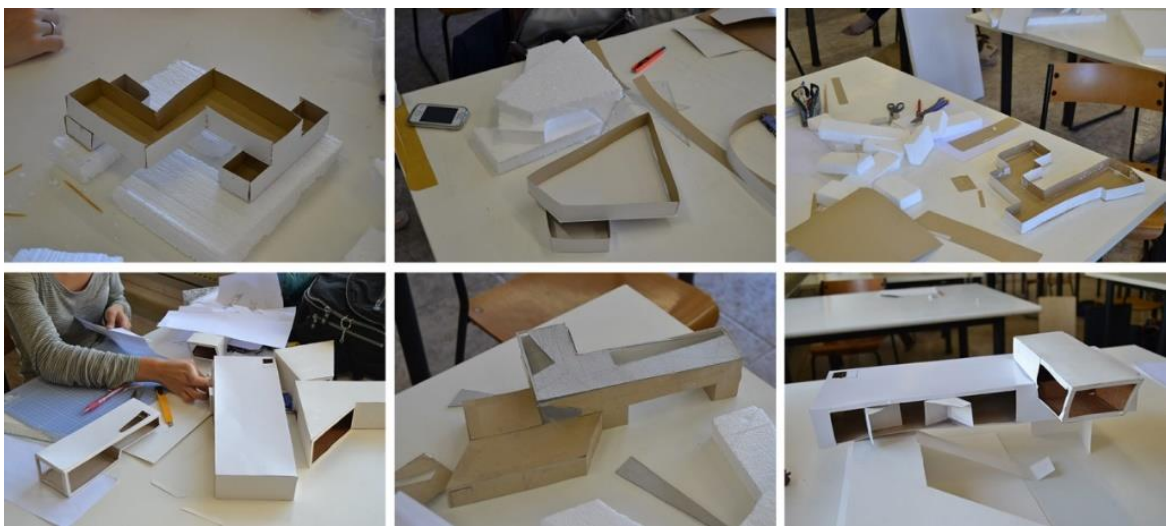

Fonte: Florio e Tagliari, 2015

Figura 5: Croquis e desenhos produzidos pelos estudantes durante o $2^{\circ}$ exercício.
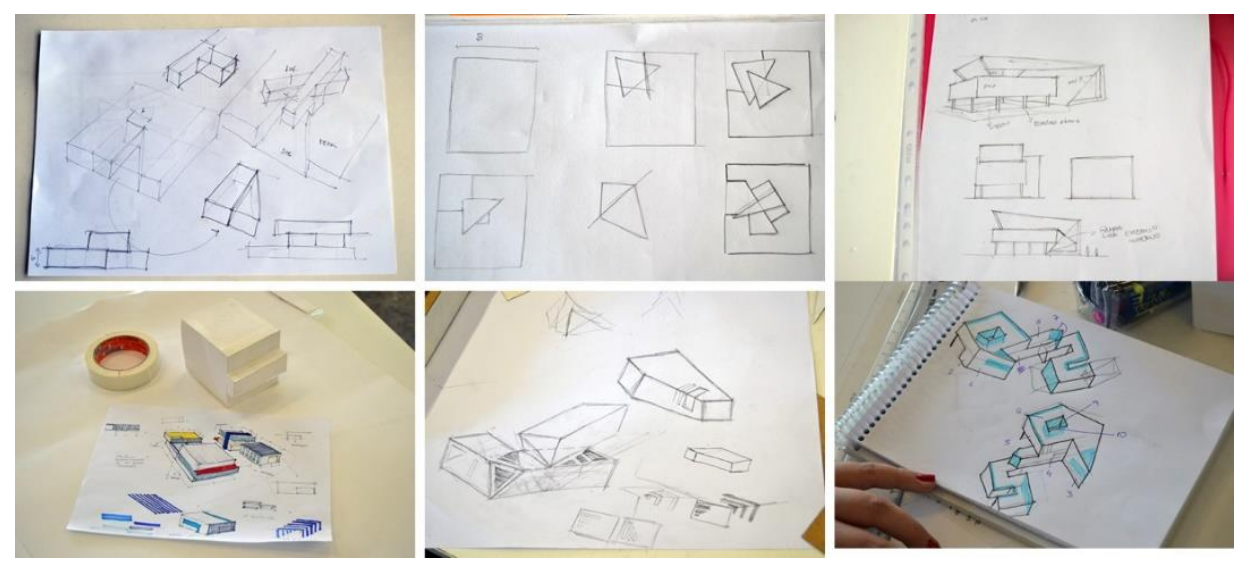

Fonte: Florio e Tagliari, 2015

Tanto na etapa de definição volumétrica como na de definição dos espaços internos foi solicitado que, a cada momento do projeto, os estudantes produzissem croquis de concepção (Figura 5) e desenhos de observação. Notou-se claramente a dificuldade dos estudantes em antecipar e expressar ideias por meio de desenhos, particularmente de formas diagonais. O que ocorreu, na maioria dos casos, foi que os estudantes realizaram desenhos de observação após a ideia ter sido lançada num modelo físico.

$\mathrm{Na}$ etapa final de produção da maquete de apresentação em poliestireno, o rigor geométrico e a precisão foram importantes para a definição da organização das formas no espaço tridimensional (Fig. 6). O poliestireno de $2 \mathrm{~mm}$ é um material mais espesso e mais rígido, propiciando maior exatidão e melhor estabilidade para o modelo físico. O objetivo foi estudar as aberturas com maior precisão, definir espessuras de paredes, e investigar a estabilidade da proposta, particularmente em relação aos volumes protuberantes, que definiam balanços.

Figura 6: Maquetes finais produzidos em poliestireno pelos estudantes na etapa final do $2^{\circ}$ exercício
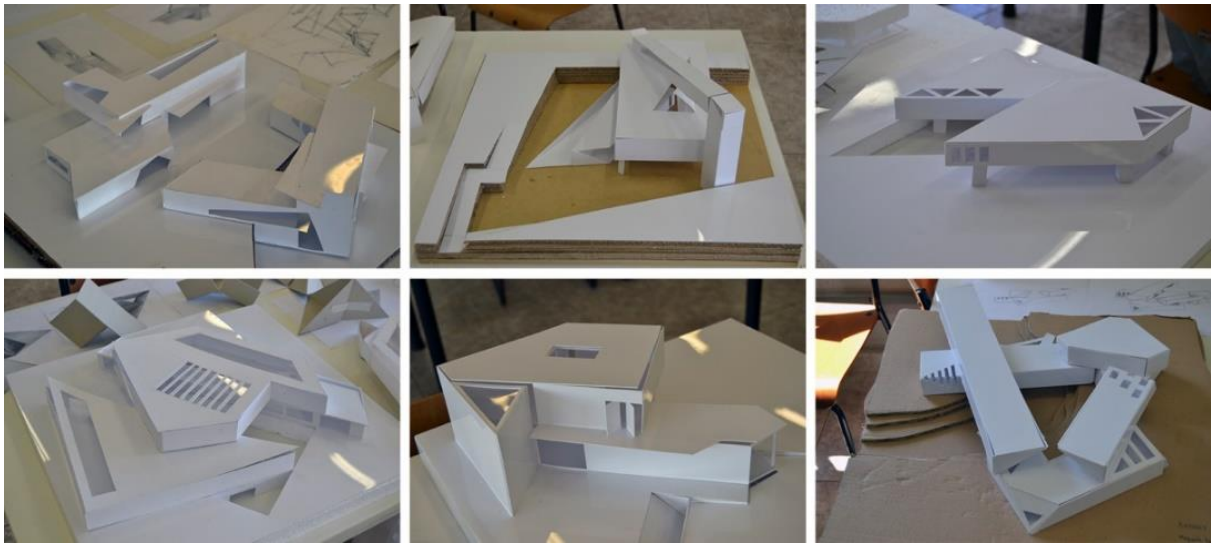

Fonte: Florio e Tagliari, 2015. 
Figura 7: Desenhos de observação da maquete final produzidos pelos estudantes na etapa final do $2^{\circ}$ exercício
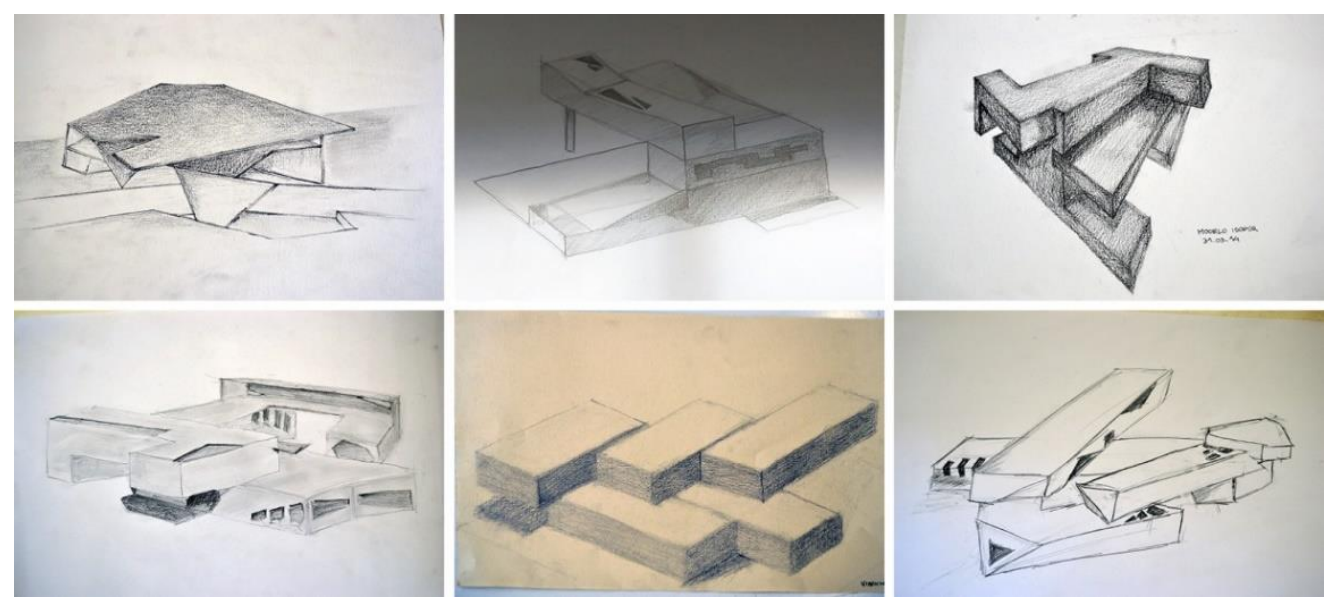

Fonte: Florio e Tagliari, 2015

Cada tipo de material empregado exigiu o uso de diferentes ferramentas. O corte do isopor, do papel paraná e do poliestireno foi realizado com o estilete. Mas diferentes tipos de cola foram utilizados para o isopor, para o papel e para o poliestireno. Consequentemente, a realização do projeto ocorreu por aproximações sucessivas, desde os modelos mais rudimentares até aquele com melhor acabamento e maior precisão geométrica e de execução.

Os desenhos de observação da maquete final realizados pelos estudantes tiveram o objetivo de fazê-los representar bidimensionalmente aquilo que viam tridimensionalmente no espaço (Fig. 7). Além disso, a intenção foi motivá-los a apreciar a forma e os espaços resultantes a partir de desenhos expressivos, que enaltecessem e valorizassem os principais pontos de observação do edifício proposto.

Além de ser um exercício que incorpora conhecimentos trazidos pela disciplina de desenho de observação e de desenho técnico, os estudantes tiveram a oportunidade de julgar o que fizeram, e perceber importantes relações espaciais, proporção, ritmo e harmonia entre as partes e o todo do edifício concebido.

\section{RESULTADOS OBTIDOS}

\section{$1^{\circ}$ Exercício: Dobraduras}

Os resultados obtidos deste exercício permitem concluir que os alunos possuem poucas habilidades manuais para lidar com materiais, sobretudo no uso de instrumentos como régua, compasso e estilete. A execução das dobraduras exigiu dos estudantes uma capacidade de pensar espacialmente e expressar manualmente o que pretendiam, assim como uma capacidade de ordenar as etapas de execução de modo a atingir seus objetivos.

É importante destacar que a maioria dos alunos se surpreendeu com as infinitas combinações possíveis entre a definição das dobraduras e o jogo de luz e sombra decorrente da posição das superfícies no espaço. Isso nos leva a deduzir que eles não tinham noção do resultado previamente em mente. Mesmo quando realizavam esboços, eles perceberam que os vincos nas superfícies e a direção das dobras propiciavam múltiplas escolhas, que não podiam ser previstas inicialmente sem tentativa e erro.

Os resultados obtidos no primeiro exercício foram essenciais para o entendimento dos procedimentos de produção de artefatos tridimensionais a partir de superfícies bidimensionais, assim como sobre o conceito de enrijecimento da forma a partir das sucessivas dobraduras no espaço. Além disso, estimulou-se a produção de ideias diretamente em modelos físicos rudimentares, e, particularmente, a produção de coberturas constituídas por uma geometria formada por faces triangulares, que normalmente os estudantes não concebem por meio de desenhos manuais.

\section{$2^{\circ}$ Exercício: Projeto do Pavilhão Amilcar de Castro}

Os resultados obtidos na concepção e no desenvolvimento do Pavilhão Amilcar de Castro permitem extrair algumas importantes conclusões parciais. A primeira é que os dois tipos de modelagem - massa versus superfície, e os três tipos de materiais empregados - isopor, papel duplex/paraná e poliestireno, possuem uma relação direta com o tipo de pensamento visual e espacial realizado pelo estudante. Isso ocorre por quatro fatores. 
O primeiro fator é que a ideia inicial exige uma abstração sobre a forma volumétrica que se deseja alcançar. Isso pode ser mais facilmente obtido por meio de peças de isopor, que privilegiam o estudo da "massa" volumétrica a partir das principais partes do edifício. Após essa fase inicial, quando foram exploradas diferentes volumetrias, na fase seguinte pode-se selecionar a ideia mais promissora, e, a partir daí, definir as superfícies que constituem essa "massa" tridimensional inicial, explorando assim a relação entre a forma externa e o espaço interno. Contudo, devido à espessura do papel, as superfícies não se mantiveram retas e planas, exigindo assim que um material mais rígido, como o poliestireno, fosse utilizado para estabilizar o modelo. Consequentemente percebe-se que há íntimas relações entre o material empregado e a possibilidade de exploração de um determinado aspecto do projeto a cada momento.

Pode-se concluir que o modelo de isopor contribuiu para definir o partido arquitetônico, isto é, o ponto de partida do projeto, que envolveu a definição inicial do número de pavimentos, setorização, esquema de circulação, volumetria. Por outro lado, o modelo constituído por superfícies privilegiou a exploração dos espaços internos, relações entre cheios e vazios, das circulações entre pavimentos, fazendo com que o aluno pensasse na função e nas relações espaciais ao mesmo tempo. Por fim, o modelo produzido com o poliestireno serviu para definir, com maior precisão, e maior acabamento, os elementos que constituem o edifício, como a espessura das paredes, as aberturas, escadas (ou rampas), e, particularmente, a estabilidade do modelo, sem deformação onde havia balanços, por exemplo.

De um modo geral, o segundo fator é que os estudantes perceberam que a fluidez das ideias tridimensionais ocorre mais rapidamente por meio de volumetrias realizadas com isopor. Neste tipo de modelo volumétrico forma e função são abstratamente tratadas de maneira rudimentar, mas que baliza o raciocínio espacial. Sem se ater a particularidades, o estudante emprega o modelo constituído por superfícies para estudar relações entre espaços internos e também entre estes e o espaço externo, de modo mais intenso e também mais tangível. O estudo da estabilidade do edifício depende do posicionamento da estrutura e da rigidez do material empregado. Assim, o modelo em poliestireno permitiu que o estudante investigasse, com maior precisão, a dimensão adequada dos balanços e os pontos de apoio necessários à estabilidade da construção.

Como é possível perceber, os domínios forma-função-técnica, balizadores na definição do projeto, são explorados com maior ou menor intensidade durante o processo de projeto. Isso nos leva a concluir que cada tipo de artefato favorece, com maior intensidade, cada um desses três domínios, que se alternam e se complementam na definição de um projeto de arquitetura.

O terceiro fator é a íntima relação entre o tipo de modelo e o pensamento visual e espacial. O modelo volumétrico favorece a produção de ideias relativas à forma, mas não em relação aos espaços internos. $O$ modelo formado por superfícies delimita espaços internos, favorecendo o estudo da relação entre a forma (aspecto externo) e o volume contido por ela. O pensamento diagramático contido no modelo volumétrico privilegia o pensamento sintético, enquanto o modelo formado por superfícies privilegia o pensamento analítico. O primeiro trata do todo, enquanto que o segundo trata das partes. Logicamente trata-se de uma generalização didática, pois é bem conhecido o fato que, em arquitetura, esses dois tipos de pensamento, o sintético e o analítico, se alternam constantemente a cada etapa do processo de projeto. Contudo, na presente experiência didática, a intenção é despertar o interesse dos estudantes na exploração dos vários domínios de projeto - forma-função-técnica, e também a alternância entre o pensamento do todo para as partes (dedutivo), ou das partes para o todo (indutivo).

Por fim, a quarta e última constatação importante a ser destacada é que os estudantes tiveram mais facilidade de ousar na proposição de formas por meio de estudos volumétricos físicos do que por meio de desenhos. Isso ocorreu devido à natureza geométrica das formas pontiagudas, e também pelo não paralelismo entre várias formas, fatores que normalmente dificultam a representação bidimensional. Assim, os desenhos vieram a partir após a produção de modelos físicos, e, também o contrário, isto é, a partir dos desenhos alguns estudantes tentavam alterar o que estava no modelo físico.

Este último delicado aspecto é importante, pois demonstra claramente a complementaridade entre desenhos e modelos físicos. Além disso, pode-se notar como é possível produzir e explorar ideias por meio de diferentes meios de representação, cuja alternância entre um e outro depende da adoção da melhor estratégia para atender às necessidades que ocorrem durante as diferentes situações de projeto.

\section{DISCUSSÃO}

Os exercícios propostos colocaram os estudantes diante de problemas reais e relevantes para o aprendizado de projeto, e, com destaque, enfatizaram o papel dos meios de representação na materialização de suas ideias. Pode-se verificar a aprendizagem significativa a partir do momento que os 
estudantes perceberam, na prática, que a matéria que estava sendo estudada se relacionava, de modo muito próximo, com os seus próprios anseios e objetivos. Em decorrência desta constatação, notou-se uma visível imersão dos estudantes na investigação e na produção de variadas propostas. Isso ocorreu pela motivação intrínseca que foi estimulada pelos professores na disciplina. Rapidamente os alunos entenderam a liberdade que teriam para criar formas que não estavam habituados.

$O$ incentivo maior veio a partir dos primeiros resultados e avanços positivos, que eles viam acontecer a cada aula. A desconfiança e o medo deram lugar à fruição e ao prazer da descoberta, e, assim, as ideias passaram a fluir com maior naturalidade, fazendo com que os alunos naturalmente começassem a hibridizar os meios de representação, alternando a produção de modelos com a de desenhos. Convencidos que este aprendizado seria importante nas aulas de projeto, os estudantes passaram a incorporar um novo hábito de se expressar por diferentes meios de representação.

Os professores assumiram o papel de facilitadores de aprendizado, instigando os estudantes a investigar diferentes possibilidades de realização de seus projetos. A suspensão temporária de conclusões apressadas foi incentivada pelos professores, de modo a cultuar a dúvida e a incerteza, sem a preocupação de encontrar uma solução imediata. Os estudantes produziram ideias diferentes entre si com a finalidade de investigar as possibilidades e o potencial de cada solução. Esse incentivo a uma ampla investigação foi muito benéfico ao projeto, pois a solução selecionada foi decorrente de uma escolha consciente e reflexiva.

Deliberadamente os professores fizeram com que cada estudante retardasse o momento da seleção da solução desejada, de modo a fazê-lo pensar o maior tempo possível sobre os problemas inerentes a cada fase do processo. Foi por meio de uma posição ativa dos estudantes que eles adquiriram conhecimentos. Foi o real comprometimento que os impulsionou a buscar significados em suas próprias ações para atingir seus propósitos. Tudo isso os conduziu a produzir vários artefatos, desenhos e modelos.

Os esboços e desenhos realizados durante a concepção da forma e dos espaços do edifício não tiveram a mesma qualidade e precisão dos modelos realizados. Isso ocorreu devida a falta de estímulo e de hábito de desenhar formas constituídas por ângulos agudos e planos não paralelos entre si. Por mais imperfeito que um modelo físico fosse realizado, ele estava em escala, e manteve a proporção entre as partes e o todo durante todas as fases de criação e de desenvolvimento das ideias.

Figura 8: Fotos do interior dos modelos físicos no projeto do Pavilhão realizado pelos estudantes.
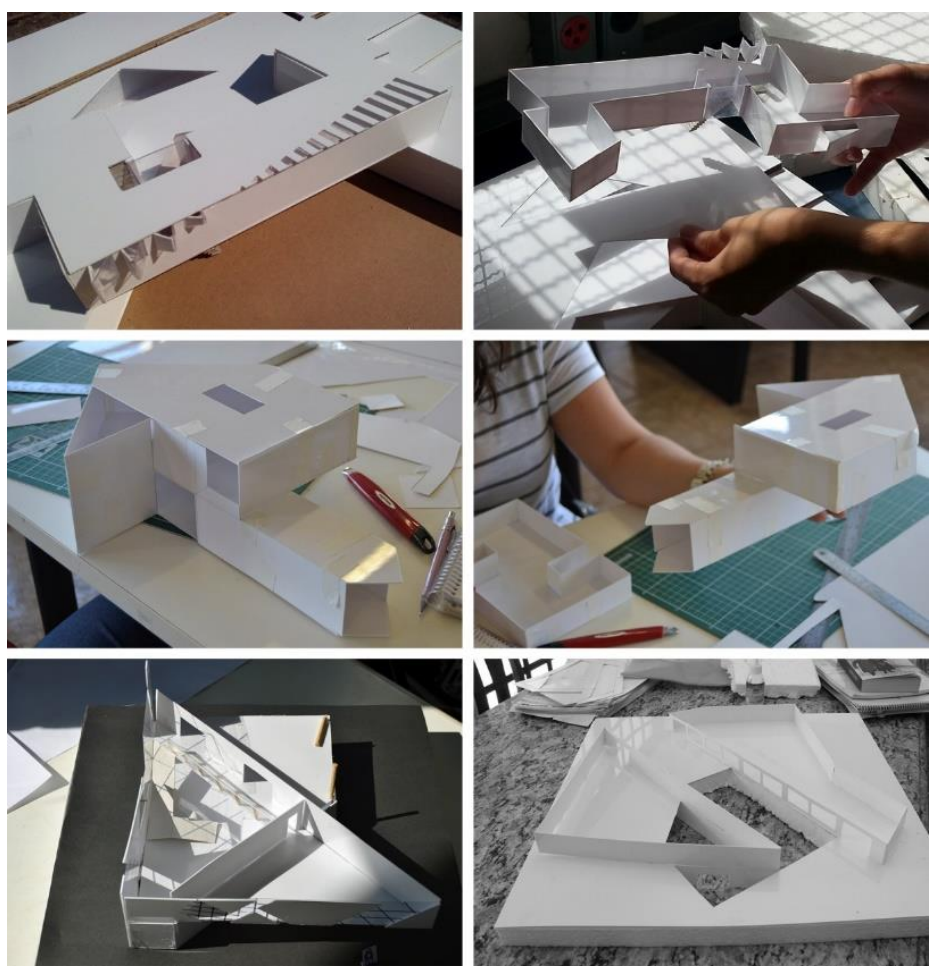

Fonte: Florio e Tagliari, 2015

Outra constatação é que as formas geradas, os vazios internos e os tipos de aberturas estudados por meio de modelos físicos foram mais ousadas e mais expressivas do que as ideias esboçadas nos desenhos. Tudo indica que a tangibilidade impõe um modo de trabalhar que envolve a visão e o tato, intensificando o nível de compreensão espacial gerada a partir das formas que eram montadas a cada momento. A 
bidimensionalidade achata a profundidade de espaço, e não permite explorar todas as faces do objeto simultaneamente, como ocorre no modelo físico.

Por ser tridimensional, e poder-se desmontar, girar ou caminhar em torno do modelo físico, este tipo de artefato tem grande capacidade de transmitir informações imediatas sobre a natureza da proposta arquitetônica e, naturalmente, sobre o que se deseja conceber (Fig. 8). Para alunos no início do curso, desenhos ortogonais impõem uma separação rígida entre planta, corte e elevação, dificultando o pleno entendimento do espaço que realmente está sendo concebido. Entretanto, nesta experiência didática todos os meios de representação complementaram-se nas suas respectivas competências de registro da concepção e da materialização do espaço arquitetônico durante a realização do projeto.

Para estudantes dos dois primeiros anos, parece que o hábito de iniciar o projeto pela planta faz com que eles privilegiem a função, em detrimento da forma e da técnica-construtiva. Como o modelo físico, de um modo geral, é pouco explorado durante as aulas de projeto para gerar e explorar ideias, o estudante é conduzido a um raciocínio mais bi do que tridimensional. Neste sentido percebe-se a importância do professor de projeto para alertar os seus alunos sobre o fato que cada meio de expressão e de representação interferi e contribui para o raciocínio projetual.

Figura 9: Exposição e debate final no atelier sobre os resultados obtidos no $2^{\circ}$ exercício.
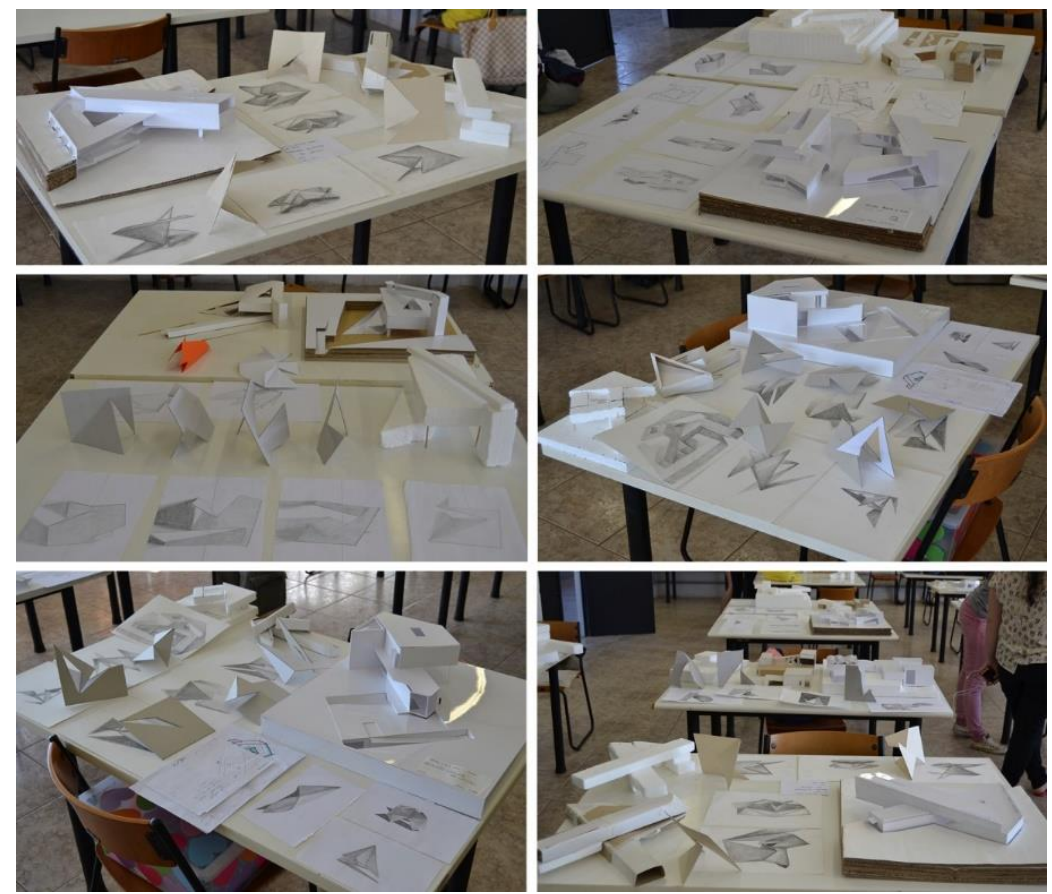

Fonte: Florio e Tagliari, 2015

Foi visível a exploração das variadas formas e de espaços internos produzidos durante a concepção e o desenvolvimento do projeto do Pavilhão. A tridimensionalidade e a tangibilidade dos modelos físicos favoreceram a investigação do encadeamento dos espaços internos, e suas relações com os espaços externos. Como é possível notar na Figura 8, espaços intrincados podem ser explorados a partir da utilização dos modelos físicos na prática projetual.

As habilidades manuais, tanto para a elaboração de desenhos como para produção de modelos físicos, podem ser plenamente estimuladas e desenvolvidas a partir de constantes exercícios. Consequentemente, novos hábitos podem ser adquiridos com o incentivo e a devida explicação necessária sobre a importância de tais artefatos para projetar com maior qualidade.

Contatou-se durante os exercícios que há estudantes que já possuem uma predisposição para entender a complementaridade dos vários meios de expressão e de representação. Contudo, sem o devido aconselhamento do professor, no momento certo de desenvolvimento de um projeto de arquitetura, o estudante pode abandonar precocemente a exploração de ideias por diferentes meios de expressão, ocasionando uma falha na sua formação.

Notou-se também que não basta explicar verbalmente o que está sendo solicitado a cada momento. Assim, durante as aulas os professores incentivavam os estudos a partir de pequenos experimentos realizados diante deles. É importante mostrar como realizar o que está sendo solicitado, seja desenhando, explicando 
noções geométricas, seja cortando ou dobrando o papel, seja ordenando as partes e o todo em princípios compositivos norteadores de projeto. Deste modo, a partir da hibridação de meios de expressão, as instruções e orientações fornecidas a cada estudante pelos professores durante a elaboração do projeto permitiram que eles "enxergassem" o que de fato estavam fazendo, e se tornassem conscientes das funções comunicativas desses artefatos.

Pode-se afirmar que o exercício projetual foi bem sucedido, particularmente pelo grau de novidade no enfrentamento de problemas para os estudantes a partir deste tipo de abordagem. Estudantes tendem a se contrapor, ou mesmo rejeitar, àquilo que já possuem como uma experiência precedente, que os faz crer que já sabem como agir. Este fato tem sido comprovado por pesquisadores na área de educação. Mas o problema pode ser contornado quando os professores explicam o que se almeja alcançar com tal exercício, destacando os benefícios para o aprendizado dos alunos.

Os estudantes tendem a negligenciar fatores importantes nas diversas tomadas de decisões que ocorrem durante o processo de projeto. Em parte isso ocorre porque às vezes já possuem "uma opinião formada" a respeito, obtida a partir de uma pequena experiência passada. Deste modo, a partir de poucas evidências, o estudante apressa-se a resolver o problema de modo precoce, sem a devida atenção aos múltiplos aspectos envolvidos no processo. Por conseguinte, os exercícios propostos tiveram a finalidade de fazê-los superar a ansiedade em solucionar o problema, fazendo-os refletir sobre vários domínios antes de tomar uma decisão.

Superados os preconceitos de explorar manualmente os artefatos, e, superada a ideia fixa de uma única solução, os alunos passaram a produzir muitos artefatos, tornando a sala de aula num verdadeiro lugar para a experimentação. Logo se percebeu que a qualidade do aprendizado do aluno dependeu substancialmente do seu envolvimento com aquilo que de fato ele precisava e queria aprender durante o processo de projeto. Assumir riscos e enfrentar os obstáculos e dificuldades fez parte do processo criativo. Assim, pode-se afirmar que, de um modo geral, os estudantes perderam o medo de enfrentar suas dúvidas e as incertezas inerentes ao processo de projeto.

É importante destacar que os estudantes apresentaram várias dificuldades de pensar durante a realização do segundo exercício proposto. Parte dos alunos tendeu a pensar de modo apressado, tomando decisões de modo impulsivo, sem o devido amadurecimento da ideia, investindo pouco no exame mais profundo de alternativas. Os professores tiveram que orientar ações pontuais, de modo a incentivar a produção de ideias alternativas para o mesmo problema.

Parte dos alunos pensou de modo limitado, sem considerar ou examinar outros pontos da vista. Havia alunos com pensamento nebuloso, descuidado, impreciso, que, ao contrário do pensamento limitado, não sabia qual direção seguir diante de várias alternativas sem relação entre si. Por fim também havia alunos com pensamento alastrado, sem organização geral, o que os fazia falhar para avançar ou para concluir alguma ideia. $O$ papel dos professores foi justamente identificar cada tipo de pensamento e induzir cada estudante a aceitar outro ponto de vista, ou criar critérios para a seleção de uma ideia, ou mesmo orientar na organização da sequência de decisões a serem tomadas.

Por fim, o conhecimento-na-ação ocorreu no momento que os alunos se conscientizaram sobre as ações que praticavam. O real significado das instruções fornecidas pelos professores só foi incorporado pelos estudantes a partir do momento que eles aplicavam durante a prática projetual. Por conseguinte, o saber teórico e saber prático se aproximaram, de modo a contribuir na formação e na preparação dos estudantes para o enfrentamento de problemas de projeto, e, particularmente, alertar sobre o papel dos modelos físicos e dos desenhos nesse processo.

\section{CONSIDERAÇÕES FINAIS}

A fragmentação das matérias, em diferentes disciplinas dos Cursos de Arquitetura, muitas vezes dificulta o ensino de projeto e dos meios de representação de arquitetura. Normalmente a disciplina de projeto exige claras noções e bons conhecimentos de outras disciplinas cursadas no mesmo período, mas que nem sempre os estudantes conseguem incorporar no exercício de projeto. Embora tenha sido realizada com várias limitações, a presente experiência didática relata como uma disciplina de representação pode se aproximar à de projeto.

A alternância entre pensar e fazer é fundamental na prática projetual. Sólidos conceitos são balizadores das ações de projeto. Contudo, somente no momento em que são colocados em prática é que se pode validar a pertinência de cada ideia dentro do contexto do projeto que está sendo realizado. 
Ademais o ensino na disciplina Modelos e Maquetes não pode ser algo meramente direcionado para atividades práticas. O ponto de vista que se argumenta neste texto é que os estudantes podem aprender a explorar os meios de representação a partir de experiências projetuais, e não a partir de técnicas meramente operacionais. Neste sentido não se trata apenas de ensinar como produzir modelos e maquetes, na verdade trata-se de ensinar a pensar a partir dos artefatos que são produzidos durante 0 processo de projeto, o que inclui desenhos, modelos físicos e modelos computacionais. Nesta visão não basta ensinar técnicas; é necessário fazer com que os estudantes aprendam a conceituar e a pensar a partir dos artefatos que eles próprios produzem durante a prática reflexiva de projeto, como um modo de externalizar seus pensamentos.

Serão necessárias ainda muitas pesquisas para avançar nos conceitos tratados neste texto, sobretudo em relação ao papel do ensino de modelos e maquetes em benefício do processo de projeto. Seguindo o que os bons educadores costumam afirmar em relação à assimilação do conhecimento: o mais importante não é ensinar, mas fazer com que os alunos aprendam a apreender.

\section{REFERÊNCIAS}

AINSWORTH, S. The functions of multiple representations. Computers \& Education, v. 33, p. 131-152, 1999.

AINSWORTH, S.; VANLABEKE, N. Multiple forms of dynamic representation. Learning and Instruction, v. 14, p. 241255, 2004.

BARON, J. B.; GRANATO, L.; SPRANCA, M.; \& TEUBEL, E. Decision-making biases in children and early adolescents: Exploratory studies. Merrill-Palmer Quarterly, v.39, n.1, 22-46, 1993.

DEWEY, John. How to Think. Boston: D. C. Heath \& Co Publishers, 1910.

IORDANOVA, A. Computational Environments with Multimodal Representations of Architectural Design Knowledge. International Journal of Architectural Computing, v. 8, n. 4, p.439-460, 2010.

KAHNEMAN, Daniel. Thinking, Fast and Slow. New York: Farrar, Straus and Giroux, 2011.

KVAN, Thomas; THILAKARATNE, Ruffina. Models in the Design Conversation: Architectural vs. Engineering. International Conference of the Association of Architecture Schools of Australasia, AASA, 2. Proceedings ... Melbourne, 28-30 September, 2003, p.1-11.

OEHLBERG, Lora; LAU, Kimberly; AGOGINO, Alice. Tangible interactions in a digital age: Medium and graphic visualization in design journals. Artificial Intelligence for Engineering Design, Analysis and Manufacturing, AIEDAM, v.23, p.237-249, 2009.

PERKINS, David N. Outsmarting IQ: the emerging science of learnable intelligence. New York: The Free Press, 1995.

RITCHHART, Ron; PERKINS, David N. Learning to Think: The Challenges of Teaching Thinking. In: HOLYOAK, Keith J.; MORRISON, Robert G. (Ed.). The Cambridge Handbook of Thinking and Reasoning. Cambridge: Cambridge University Press, 2005, Chapter 32, p.775-802.

ROGERS, C. R. Liberdade para Aprender. 4⿳亠丷. Edição. Belo Horizonte: Interlivros, 1978.

SCHÖN, Donald. Educando o Professional Reflexivo: um novo design para o ensino e a aprendizagem. Porto Alegre: Artes Médicas Sul, 2000.

. Designing as Reflective Conversation with the Materials of a Design Situation. Research in Engineering Design, v.3, p.131-147, 1992.

NOTA DO EDITOR (*) O conteúdo do artigo e as imagens nele publicadas são de responsabilidade do(s) autor(es). 